\title{
STUDY ON CAUSES OF MORTALITY IN LION-TAILED MACAQUE (MACACA SILENUS) AT ARIGNAR ANNA ZOOLOGICAL PARK, VANDALUR
}

\author{
N. Krishnakumar ${ }^{1}$ and A. Manimozhi ${ }^{2}$ \\ ${ }^{1}$ Director, ${ }^{2}$ Biologist \\ Arignar Anna Zoological Park, Vandalur, Tamil Nadu, India.
}

\begin{abstract}
Knowledge of death in captive animals is essential to study diseases in captivity. Arignar Anna Zoological Park has recorded the cause of death in Lion-tailed Macaques from 1988-1999 at the zoos veterinary hospital. Analysis of post-mortem records indicated that trauma had been the main cause of deathof LTMs; others being, parasitic infectious diseases, heat stroke and heart attack.
\end{abstract}

\section{Keywords}

Arignar Anna Zoological Park, Lion-tailed Macaques, mortality, captivity

\section{Introduction}

This report on causes of mortality in Lion-tailed Macaque (Macaca silenus) is presented for its potential value to scientists concerned with the problems of death in captivity. The data was compiled from the post mortem records filed in the veterinary hospital of the Arignar Anna Zoological Park (AAZP). The report covers the Lion-tailed Macaques (LTM) that died from 1988 to 1999. The factors responsible for the death are discussed.

\section{Materials and Methods}

Records of deaths, date, sex and causes of death were maintained routinely after the AAZP opened in 1985 . With the establishment of the veterinary hospital, each animal that died was autopsied to determine the cause of death. Collection records of post mortem examinations began with a LTM that died on 17 May 1988 and is continued till date. The authenticity and accuracy of these records are corroborated by evidence contained in the livestock register maintained by the office of the AAZP beginning in 1983. Knowledge of the cause of death is important to study diseases in captive animals, which is the primary function of the veterinarians and biologists. For this reason scientific personnel were vitally concerned with the accuracy of the records. To analyse the causes of death, the data was grouped into three categories, viz., trauma, parasitic infections and other factors.

\section{Observations}

The sex, date and cause of death of LTMs from 1988 to 1999 are presented in Table 1. Out of the 15 deaths that were recorded the cause of death of one animal could not be traced, therefore data on 14 LTMs have been accounted for in this study.

\section{Trauma}

Out of the 14 deaths that have occurred in LTMs during the last 10 years in Arignar Anna Zoological Park, eight (57.14\%) deaths were due to trauma (Fig. 1). Of the eight, two cases of deaths occurred due to freak accidents. Four cases of infighting deaths occurred mainly due to sudden introduction of new adult animals without prior acclimatization; and remaining two cases of death due to shock and ingestion of foreign objects. Earlier studies revealed that the originally existing troop was tolerant to introduction of sub-adults and infants (Subarayalu \& Paulraj, 1992).

\section{Parasitic infectious diseases}

Out of 14 deaths four (28.57\%) LTMs died of parasitic infectious diseases (Fig. 1). Of the four, one death was due to tuberculosis (TB) in 1988, after which necessary prophylaxis against TB was taken. Thereafter no more TB deaths were recorded. Two LTMs died of parasitic pneumonia during 1990. Regular deworming has prevented deaths due to parasitic pneumonia. One case of LTM death was observed due to acute haemorrhagic enteritis.

\section{Others}

Out of 14 deaths, two LTMs (14.29\%) died of other factors (Fig. 1). One died of heat stroke and another died of heart attack.

Of the above three categories trauma played a major role (57.14\%) in LTM deaths. 


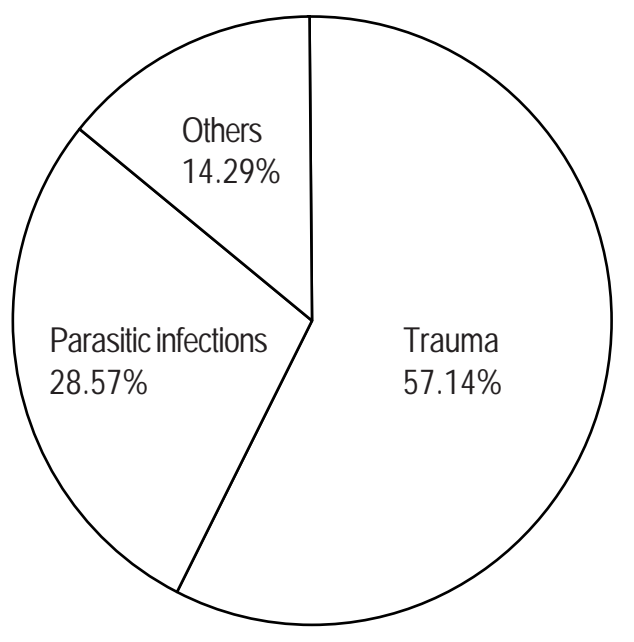

Figure 1. Percentage LTM mortalities due to various causes.

\section{Death of LTMs in relation to months (or) seasons}

Out of the 14 deaths, four deaths (28.57\%) were observed in the month of June all due to trauma and three deaths $(21.43 \%)$ noticed in July (Fig. 2). Of the three deaths in July two were due to parasitic pneumonia and one died in trauma. Two LTMs died $(14.29 \%)$ in the months of May and September. Cause of death in the month of May was observed to be heat stroke and tuberculosis; the death in September was due to trauma. Single death $(7.14 \%)$ in the months of October, November and December were observed due to acute haemorrhagic enteritis, cardiac arrest and trauma respectively.

From the above results, it is presumed that except for one death in the month of May (heat stroke) no other deaths could be correlated with seasons or climatic changes.
Table 1. Death reports of Lion-tailed Macaque in Arignar Anna Zoological Park.

\begin{tabular}{|c|c|c|}
\hline Date & Sex & Cause of death \\
\hline 17.05.88 & Male & Tuberculosis \\
\hline 18.12.88 & Female & Gangrenous wound \\
\hline 07.06 .89 & Male & $\begin{array}{l}\text { Shock due to hemorrhage in the digestive tract } \\
\text { caused by ingestion of foreign materials } \\
\text { (Aluminium) }\end{array}$ \\
\hline 15.01 .90 & Male & Acute haemorrhagic enteritis \\
\hline 28.06 .90 & Female & $\begin{array}{l}\text { Fatal contusion and damaged tissue caused } \\
\text { by broken bone }\end{array}$ \\
\hline 012.07 .90 & Female (Ruban) & Toxaemia and parasitic pneumonia \\
\hline 17.07 .90 & Female & Toxaemia and parasitic pneumonia \\
\hline 08.06.92 & Male & Shock due to multiple bitten injury \\
\hline 10.09.91 & Female & Shock \\
\hline 08.09 .94 & Female (Malar) & $\begin{array}{l}\text { Shock due to internal hemorrhages might be } \\
\text { due to fallen tree }\end{array}$ \\
\hline 16.11.95 & Female (Radha) & Cardiac arrest \\
\hline 22.06.95 & Male (Sankar) & Aspiration \\
\hline 21.07.95 & Female (Geetha) & Aspiration \\
\hline 22.05.97 & Female (Rukkmani) & Heat stroke \\
\hline
\end{tabular}

Death in relation to sex

The highest percentage of mortality was observed in females $(57.14 \%)$ than in males $(42.86 \%)$. This could be attributed to introduction of more females (5) rather than males (3) in the existing group of LTMs.

\section{Reference}

Paulraj, S. and S.S. Naidu (1987). Establishment of a social group in Lion-tailed Macaques (Macaca silenus). Animal Keepers' Forum pp. 337-338.

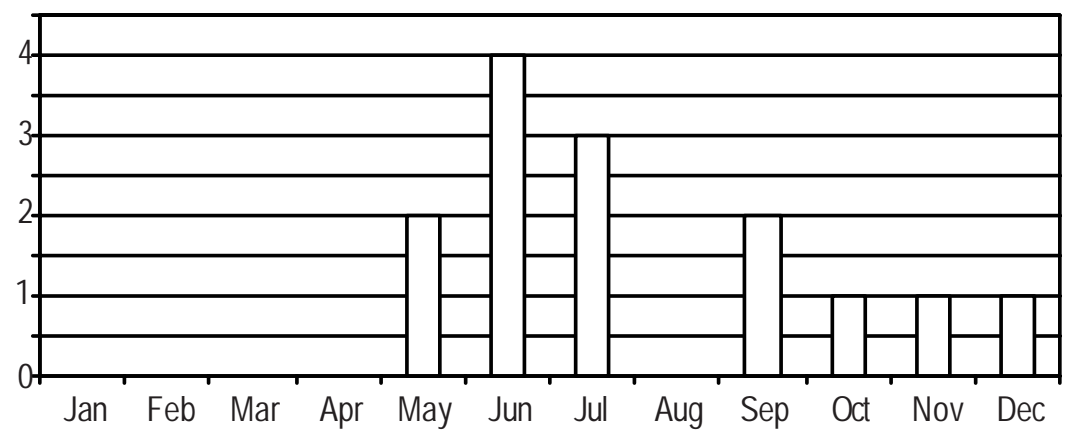

Figure 2. LTM mortalities in different months over a 10-year period. 